\title{
Haftung und Kompensation bei Straßenverkehrsunfällen
}

Eine rechtsvergleichende Untersuchung nach deutschem und neuseeländischem Recht

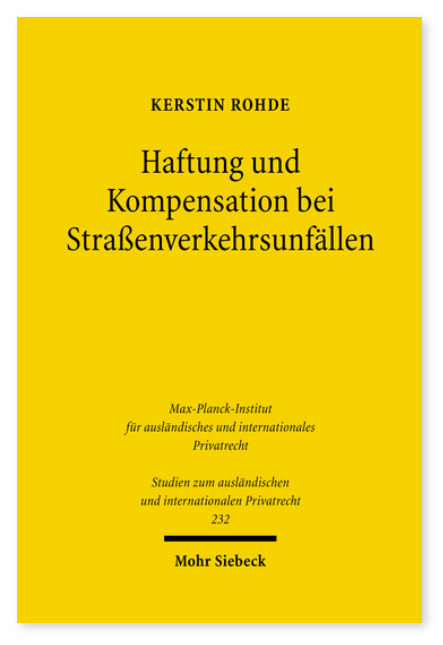

2009. XXI, 416 Seiten. StudIPR 232

ISBN 978-3-16-151417-3

DOI 10.1628/978-3-16-151417-3

eBook PDF 94,00€

ISBN 978-3-16-150241-5

fadengeheftete Broschur 94,00€
Straßenverkehrsunfälle sind im menschlichen Alltag zu einem Massenphänomen geworden. Es war daher Aufgabe der Gesetzgeber nahezu aller Länder, den Schadensausgleich bei Straßenverkehrsunfällen sicherzustellen. Der neuseeländische Gesetzgeber schuf mit dem Accident Compensation Scheme ein bisher weltweit einmaliges Entschädigungssystem für den Ausgleich von Personenschäden, die durch einen Unfall hervorgerufen werden. Auch der deutsche Gesetzgeber richtete mit der Gefährdungshaftung und der Kraftfahrzeug-Haftpflichtversicherung ein System ein, um den Schadensausgleich bei Straßenverkehrsunfällen zu gewährleisten. Kerstin Rohde untersucht den Schadensausgleich bei Straßenverkehrsunfällen in beiden Rechtssystemen mit Blick auf die Voraussetzungen zur Begründung eines Schadensersatzanspruchs, Art und Umfang der Schadensersatzleistungen sowie die Abwicklung von Schadensfällen.

Kerstin Rohde Geboren 1980; Studium der Rechtswissenschaften in Erlangen; 2006 LL.M.-Studium in Wellington/Neuseeland; 2009 Promotion; seit 2008 Rechtsreferendarin am Oberlandesgericht Nürnberg.
Jetzt bestellen:

https://mohrsiebeck.com/buch/haftung-und-kompensation-bei-strassenverkehrsunfaellen-9783161514173?no_cache=1 order@mohrsiebeck.com

Telefon: +49 (0)7071-923-17

Telefax: +49(0)7071-51104 